\title{
A Malarial Cysteine Proteinase Is Necessary for Hemoglobin Degradation by Plasmodium falciparum
}

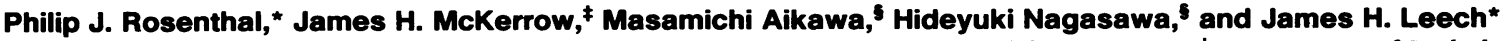 \\ ${ }^{*}$ Department of Medicine, San Francisco General Hospital, San Francisco, California $94110 ;{ }^{\ddagger}$ Department of Pathology, University of \\ California, San Francisco, California 94143; \$Institute of Pathology, Case Western Reserve University, Cleveland, Ohio 44106
}

\begin{abstract}
To obtain free amino acids for protein synthesis, trophozoite stage malaria parasites feed on the cytoplasm of host erythrocytes and degrade hemoglobin within an acid food vacuole. The food vacuole appears to be analogous to the secondary lysosomes of mammalian cells. To determine the enzymatic mechanism of hemoglobin degradation, we incubated trophozoite-infected erythrocytes with peptide inhibitors of different classes of proteinases. Leupeptin and L-transepoxy-succinyl-leucylamido-(4-guanidino)-butane (E-64), two peptide inhibitors of cysteine proteinases, inhibited the proteolysis of globin and caused the accumulation of undegraded erythrocyte cytoplasm in parasite food vacuoles, suggesting that a food vacuole cysteine proteinase is necessary for hemoglobin degradation. Proteinase assays of trophozoites demonstrated cysteine proteinase activity with a pH optimum similar to that of the food vacuole and the substrate specificity of lysosomal cathepsin $L$. We also identified an $M_{\mathrm{r}} \mathbf{2 8 , 0 0 0}$ proteinase that was trophozoite stage-specific and was inhibited by leupeptin and E-64. We conclude that the $M_{\mathrm{r}} \mathbf{2 8 , 0 0 0}$ cysteine proteinase has a critical, perhaps rate-limiting, role in hemoglobin degradation within the food vacuole of Plasmodium falciparum. Specific inhibitors of this enzyme might provide new means of antimalarial chemotherapy.
\end{abstract}

\section{Introduction}

The human malaria parasite Plasmodium falciparum has a 48-h life cycle within host erythrocytes that is responsible for all of the clinical manifestations of falciparum malaria. During the erythrocytic cycle the intracellular parasite develops from a ring stage into a more metabolically active trophozoite, divides asexually and becomes a schizont, and finally ruptures the host erythrocyte, releasing daughter merozoites that invade other erythrocytes to reinitiate the cycle. Several lines of evidence indicate that the degradation of host erythrocyte hemoglobin provides an important reservoir of amino acids for protein synthesis by intraerythrocytic malaria parasites. First, malaria parasites have a limited capacity for synthesizing amino acids, and the quantity of free amino acids within erythrocytes is not

This work was presented in part at the Annual Meeting of the American Federation for Clinical Research, San Diego, CA, 1-4 May 1987.

Address correspondence to Dr. Philip Rosenthal, San Francisco General Hospital, Building 30, Room 406, 1001 Potrero Avenue, San Francisco, CA 94110.

Received for publication 27 January 1988 and in revised form 2 May 1988.

J. Clin. Invest.

(c) The American Society for Clinical Investigation, Inc.

$0021-9738 / 88 / 11 / 1560 / 07 \$ 2.00$

Volume 82, November 1988, 1560-1566 sufficient for the needs of the parasite (1). Second, the hemoglobin content of infected erythrocytes decreases $25-75 \%$ during the life cycle of erythrocytic parasites $(2,3)$, and the concentration of free amino acids is greater in infected erythrocytes than in uninfected erythrocytes (4). Third, the composition of the amino acid pool of infected erythrocytes is similar to the amino acid composition of hemoglobin (5-7). Fourth, the infection of erythrocytes containing radiolabeled hemoglobin is followed by the appearance of labeled amino acids in parasite proteins (8-10).

Hemoglobin degradation occurs predominantly during the trophozoite stage of the erythrocytic life cycle of $P$. falciparum. Trophozoites ingest erythrocyte cytoplasm and transport it within vesicles to a large central food vacuole $(11,12)$, where the hemoglobin-rich cytoplasm is degraded. In the food vacuole the heme moiety precipitates and is a major component of malarial pigment (13), and globin is hydrolyzed to its constituent free amino acids. The food vacuole of $P$. falciparum is an acidic $(14,15)$, membrane-bound (11) compartment where proteins are degraded, and therefore it appears to be analogous to the secondary lysosomes of mammalian cells, where multiple proteinases hydrolyze proteins at acid $\mathrm{pH}(16,17)$.

The enzymatic mechanism of globin degradation within the malarial food vacuole is unknown. In previous studies, aspartic proteinases that degraded denatured hemoglobin were isolated from malaria parasites (18-20). However, denatured hemoglobin is a nonspecific substrate that can be hydrolyzed by many proteinases, and the biological role of the aspartic proteinases cannot be determined from these studies. To determine the enzymatic mechanism of globin degradation in the trophozoite food vacuole we first studied the effects of class-specific proteinase inhibitors on intact parasites. We found that two peptide inhibitors of cysteine proteinases blocked globin degradation in the food vacuole of $P$. falciparum trophozoites. We also identified a cysteine proteinase of trophozoites that was inhibited by the same two proteinase inhibitors and had biochemical properties that were similar to those of the lysosomal cysteine proteinase cathepsin L. Our results suggest that the cysteine proteinase we identified has a critical role in hemoglobin degradation in the food vacuole of $P$. falciparum trophozoites.

\section{Methods}

Reagents. Leupeptin, chymostatin, pepstatin A, L-transepoxysuccinyl-leucylamido-(4-guanidino)-butane (E-64), ${ }^{1} \quad N$-ethylmaleimide (NEM), PMSF, 1,10-phenanthroline, DTT, cysteine, and glutathione were from Sigma Chemical Co. (St. Louis, MO). Azocoll,

1. Abbreviations used in this paper: AMC, amino-4-methyl-coumarin; E-64, L-transepoxy-succinyl-leucylamido-(4-guanidino)-butane; EM, electron microscopy; NEM, $N$-ethylmaleimide; Z-V-L-R-AMC, valine-leucine-arginine AMC; $\mathrm{Z}$, benzyloxycarbonyl. 
an insoluble diazonium dye-collagen complex that releases soluble diazo-containing fragments with proteolysis, was purchased from $\mathrm{Cal}$ biochem-Behring Corp. (La Jolla, CA). $\left[{ }^{14} \mathrm{C}\right]$ Methemoglobin (30 $\mathrm{mCi} / \mathrm{g}$ ) was from DuPont New England Nuclear (Wilmington, DE). The following flurogenic peptide substrates were purchased from Enzyme Systems Products (Livermore, CA): benzyloxycarbonyl (Z)-PheArg-7-amino-4-methyl-coumarin (AMC); Z-Val-Leu-Arg-AMC; Z-Arg-Arg-AMC; Z-Leu-AMC; Z-Phe-Pro-Arg-AMC; Z-Phe-AMC; Z-Ala-Arg-Arg-AMC.

Parasites and culture. Cloned parasites from a Brazilian isolate (It) were cultured in human erythrocytes and media containing RPMI-1640 (Gibco Laboratories, Grand Island, NY), $25 \mathrm{mM}$ Hepes, $50 \mu \mathrm{g} / \mathrm{ml}$ gentamicin (Schering Corp., Kenilworth, NJ), 0.27\% sodium bicarbonate, and $10 \%$ human serum (21). The cultures were synchronized by sequential treatments with $5 \%$ (wt/vol) sorbitol in PBS (22). Leukocytes and platelets were exhaustively removed from erythrocytes used for culture as previously described (23).

Transmission electron microscopy (EM) and EM autoradiography. Synchronized parasite cultures were incubated with $100 \mu \mathrm{M}$ leupeptin, $140 \mu \mathrm{M} \mathrm{E}-64$, or no inhibitor for $12 \mathrm{~h}$ and the trophozoite-infected erythrocytes were then concentrated by suspension in $0.5 \%$ (wt/vol) gelatin (Type I; Sigma Chemical Co.) in RPMI-1640 (24). The infected erythrocytes were then washed in PBS and incubated for $1 \mathrm{~h}$ in $2 \%$ glutaraldehyde, $0.05 \mathrm{M}$ phosphate, and $4 \%$ sucrose at $\mathrm{pH} 7.4$. Samples were postfixed in 1\% osmium tetroxide in Millonig's phosphate buffer, dehydrated in ethanol, and embedded in Spurr. Thin sections were stained with uranyl acetate, then lead citrate, before EM.

For EM autoradiography, leupeptin was tritium labeled by microwave discharge activation (25) and was a gift from Dr. C. T. Peng of the University of California, San Francisco. Synchronized parasite cultures were incubated with $\left[{ }^{3} \mathrm{H}\right]$ leupeptin for $12 \mathrm{~h}$ and the trophozoiteinfected erythrocytes were then concentrated, fixed, postfixed, and embedded as described above. 400-600- $\AA$-thick sections were placed on Formvar and carbon-coated copper grids and stained with uranyl acetate and lead citrate. The grids were covered with a monolayer of emulsion (Ilford, Knutsford, Cheshire, England) by the wire loop method (26). The emulsion-covered grids were kept in the dark at $4^{\circ} \mathrm{C}$ for 6 wk, developed in Microdol X (Eastman-Kodak Co., Rochester, $\mathrm{NY}$ ) for $2 \mathrm{~min}$, and fixed in Kodak rapid fixer for $2 \mathrm{~min}$. The grids were washed in $1 \mathrm{~N} \mathrm{NaOH}$ for $5 \mathrm{~min}$ and examined by EM.

Determination of the globin content of parasites. Erythrocytes infected with synchronized parasites were incubated with $100 \mu \mathrm{M}$ leupeptin, $140 \mu \mathrm{M} \mathrm{E}-64$, or no inhibitor for $15 \mathrm{~h}$. The trophozoite-infected erythrocytes were then washed in PBS and lysed with $0.1 \%$ (wt/vol) saponin (Sigma Chemical Co.) in PBS. Saponin is a neutral detergent that lyses the erythrocyte membrane but not the parasite membrane. The parasites (within erythrocyte ghosts) were washed four times in ice-cold PBS to remove all free hemoglobin. Equal numbers of parasites were solubilized with electrophoresis sample buffer [5\% (wt/ vol) SDS, $62.5 \mathrm{mM}$ Tris $\mathrm{HCl}, 5 \%$ (vol/vol) 2-mercaptoethanol, $\mathrm{pH} 6.8$ ] and electrophoresed in a $15 \%$ acrylamide gel (27). Proteins were identified by staining the gel with Coomassie Blue.

Preparation of parasite extracts for proteinase assays. Synchronized cultures of trophozoites were concentrated to $50-70 \%$ parasitemias with $0.5 \%$ gelatin/RPMI 1640 as described above. The infected erythrocytes were treated with $0.1 \%$ saponin in PBS, washed three times with ice cold PBS, and incubated (in water) in a nitrogen cavitation bomb at $4^{\circ} \mathrm{C}$ and $3,500 \mathrm{kPa}$ for $1 \mathrm{~h}$. The suspension was centrifuged $\left(13,000 \mathrm{~g}, 10 \mathrm{~min}, 4^{\circ} \mathrm{C}\right)$ and the supernatant was collected. Uninfected erythrocyte controls were treated identically.

Proteinase assays. Assays with Azocoll were performed by incubating $25 \mu$ l extract with $0.9 \mathrm{ml}$ Azocoll suspension $(5 \mathrm{mg} / \mathrm{ml}$ in $0.1 \mathrm{M}$ sodium acetate buffer, adjusted to the desired $\mathrm{pH}$ ). The samples were incubated for 6 ( $\mathrm{pH}$ profile) or 18 (inhibitor profile) h at $37^{\circ} \mathrm{C}$ with continuous shaking and centrifuged $(13,000 \mathrm{~g}$ for $2 \mathrm{~min}$ ). The supernatant was collected and its absorbance at $540 \mathrm{~nm}$ was determined.

Assays with $\left[{ }^{14} \mathrm{C}\right]$ methemoglobin were performed by incubating $25-\mu l$ aliquots of extract with $2 \mu \mathrm{l}\left[{ }^{14} \mathrm{C}\right]$ methemoglobin $(30 \mathrm{mCi} / \mathrm{g}, 0.17$ $\mathrm{mg} / \mathrm{ml}), 10 \mu \mathrm{l}$ inhibitors and/or sulfhydryl compounds, $50 \mu \mathrm{l}$ of $0.1 \mathrm{M}$ sodium acetate adjusted to the desired $\mathrm{pH}$, and water to give a final volume of $100 \mu 1$. After $4 \mathrm{~h}$ of incubation at $37^{\circ} \mathrm{C}, 50 \mu 1 \mathrm{BSA}(3 \mathrm{mg} / \mathrm{ml})$ and $50 \mu \mathrm{l}$ of $50 \%$ trichloroacetic acid were added. Samples were incubated an additional $30 \mathrm{~min}$ at $4^{\circ} \mathrm{C}$ and centrifuged $(13,000 \mathrm{~g})$. 50- $\mu 1$ aliquots of the supernatant were added to $7-\mathrm{ml}$ samples of scintillation fluid and radioactivity was determined with a scintillation counter. Controls without extract were processed simultaneously.

The rates of hydrolysis of AMC-peptide substrates were determined by measuring at different time points the fluorescence (at $460 \mathrm{~nm}$ with a 380-nm excitation wavelength) caused by the liberation of AMC. Trophozoite extract (10-50 $\mu \mathrm{l})$ was added to $1.8 \mathrm{ml}$ of buffer $(0.1 \mathrm{M}$ sodium acetate, $\mathrm{pH} \mathrm{6.0)}$ with $20 \mu \mathrm{l}$ of inhibitors or sulfhydryl compounds and water to give a $2.0-\mathrm{ml}$ volume. After a 10 -min incubation at $37^{\circ} \mathrm{C}, 20 \mu \mathrm{l}$ of substrate was added from a $5-\mathrm{mM}$ stock solution in DMSO. The slopes of fluorescence over time were compared for different substrates and different inhibitors and sulfhydryl compounds. At least six time points were obtained for each assay.

Gelatin substrate PAGE. Trophozoite-infected erythrocytes were solubilized with electrophoresis sample buffer lacking mercaptoethanol, and electrophoresed in a $12 \%$ acrylamide gel copolymerized with $0.1 \%$ gelatin (28). After electrophoresis, the gel was washed in $2.5 \%$ (vol/vol) Triton X-100 (two 30-min washes) to remove SDS. The gel was then incubated in buffer $\left(0.1 \mathrm{M}\right.$ glycine, $0.002 \mathrm{M} \mathrm{CaCl}_{2}, \mathrm{pH} 6.0$ or 7.0) at $37^{\circ} \mathrm{C}$ for $18 \mathrm{~h}$ to allow digestion of gelatin by the proteinase before staining the gel with Coomassie Blue. Proteinase activity was detected as a clear band against the blue background of the gel. To determine the effect of inhibitors on proteinase activity, the inhibitor was incubated with trophozoite-infected erythrocytes for $10 \mathrm{~min}$ before the addition of electrophoresis sample buffer, and the inhibitor was also added to the glycine buffer in which the gel was incubated after electrophoresis.

\section{Results}

Effects of proteinase inhibitors on intact parasites. When trophozoite-infected erythrocytes were incubated with the cysteine proteinase inhibitors leupeptin $(20-100 \mu \mathrm{M})$ or E-64 $(140 \mu \mathrm{M})$ for 6 or more hours, the appearance of the parasite food vacuole differed greatly from that of control parasites. Both light microscopy of Giemsa-stained parasites (not shown) and transmission EM (Fig. 1) showed that the food vacuole of leupeptin- or E-64-treated parasites was completely filled with erythrocyte cytoplasm. A similar effect of leupeptin on the $P$. falciparum food vacuole was recently reported by Dluzewski et al. (29). The food vacuole abnormality was not observed when trophozoite-infected erythrocytes were incubated with peptide inhibitors of serine proteinases ( $80 \mu \mathrm{M}$ chymostatin) or aspartic proteinases ( $75 \mu \mathrm{M}$ pepstatin), though pepstatin did cause the parasites to become pyknotic after $8 \mathrm{~h}$ of incubation.

Incubation of the parasites with leupeptin or E-64 for $24 \mathrm{~h}$ inhibited parasite differentiation and multiplication. Very few parasites developed into mature, multinucleated schizonts, and new ring stage parasites indicative of successful erythrocyte rupture and reinvasion were rarely seen. The effect of leupeptin on the parasite food vacuole was reversible. After removal of leupeptin from a culture the parasites regained a normal morphology and the subsequent ring parasitemia was $85 \%$ that of control parasites (mean of two experiments). The effect of E-64 on the food vacuole was not reversible, and after removal of E-64 the subsequent ring parasitemia was only $17 \%$ that of control parasites. 

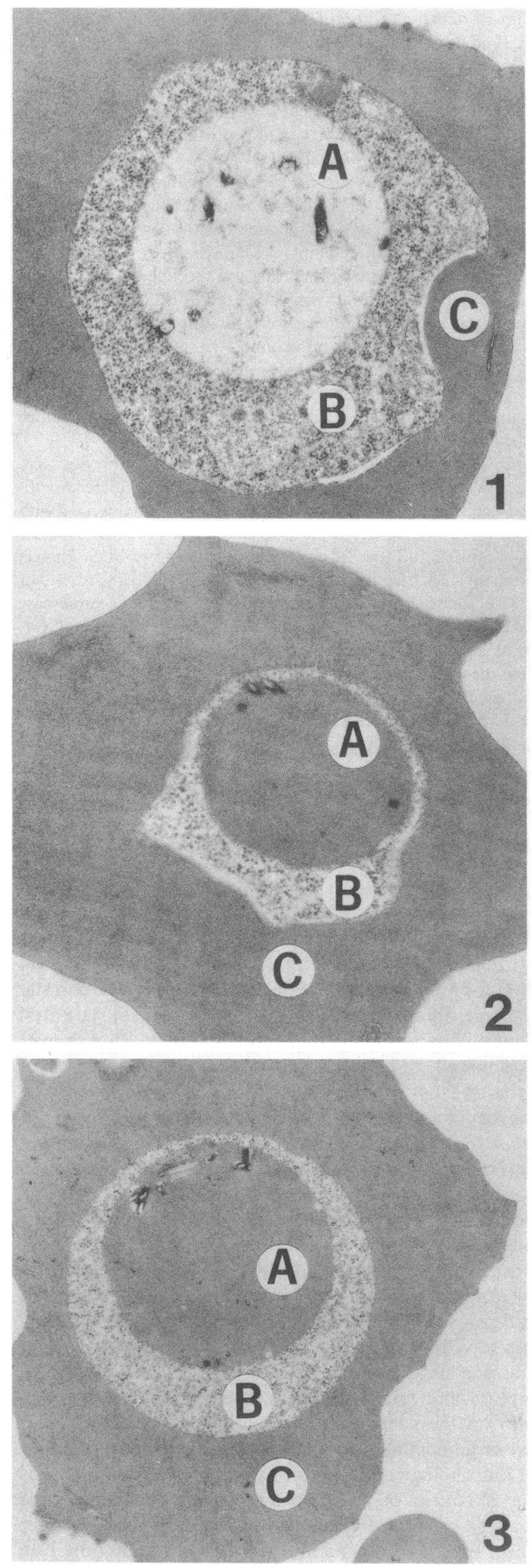

Localization of $\left[{ }^{3} \mathrm{H}\right]$ leupeptin. To test whether leupeptin could enter the $P$. falciparum food vacuole we performed EM autoradiography after incubating trophozoite-infected and uninfected erythrocytes with $\left[{ }^{3} \mathrm{H}\right]$ leupeptin. $\left[{ }^{3} \mathrm{H}\right]$ Leupeptin was observed in infected, but not uninfected, erythrocytes (50 of each were counted), and was consistently localized within the parasite food vacuole (Fig. 2). Additional $\left[{ }^{3} \mathrm{H}\right]$ leupeptin was observed in the cytoplasm of infected erythrocytes and in the parasite cytoplasm. Within the parasite cytoplasm, the $\left[{ }^{3} \mathrm{H}\right] \mathrm{leupeptin}$ appeared to be localized to vesicles containing erythrocyte cytoplasm, suggesting that leupeptin reached the food vacuole by pinocytosis and vesicular transport rather than by diffusion.

Inhibition of globin degradation by leupeptin and E-64. The observed accumulation of erythrocyte cytoplasm within the food vacuoles of parasites incubated with leupeptin and E-64 suggested that the two proteinase inhibitors had blocked the degradation of globin within the food vacuole. To test this hypothesis, we incubated trophozoite-infected erythrocytes with leupeptin, E-64, or no inhibitor, lysed erythrocyte membranes with $0.1 \%$ saponin to release erythrocyte hemoglobin, and assayed for parasite-contained globin with PAGE. Control parasites contained no detectable globin, but parasites that had been incubated with leupeptin or E-64 contained abundant undegraded globin (Fig. 3).

Proteinase activity of $P$. falciparum trophozoites. The accumulation of globin in parasites incubated with leupeptin and E-64 suggested that trophozoites contain a cysteine proteinase with a critical role in globin degradation. We therefore prepared extracts from $P$. falciparum trophozoites by nitrogen cavitation and assayed the extracts for proteinase activity with three different proteolytic substrates. With Azocoll, proteinase activity was maximal at pH 6.0 (Fig. 4), was stimulated by cysteine, was inhibited by the cysteine proteinase inhibitors leupeptin and NEM, and was not inhibited by inhibitors of other classes of proteinases (Table I). No proteinase activity was detected with extracts prepared from uninfected erythrocytes (Fig. 4).

The results with Azocoll indicated that trophozoites contain substantial cysteine proteinase activity. To substantiate this observation we used as a proteolytic substrate the synthetic peptide Z-Val-Leu-Arg-AMC. This peptide was chosen because its structure is similar to those of leupeptin and E-64, both of which contain a terminal arginine side chain adjacent to leucine. Z-Val-Leu-Arg-AMC was rapidly hydrolyzed by the trophozoite extract. The hydrolysis of this substrate was also markedly stimulated by sulfhydryl reagents and selectively inhibited by inhibitors of cysteine proteinases at $\mathrm{pH} 6.0$ (Table I).

With the substrate $\left[{ }^{14} \mathrm{C}\right]$ methemoglobin, an oxidized, denatured derivative of hemoglobin, somewhat different results were obtained (Table I). The proteinase activity of the trophozoite extract was again stimulated by sulfhydryl reagents and inhibited by cysteine proteinase inhibitors at $\mathrm{pH} 6.0$, but the

Figure 1. Effect of cysteine proteinase inhibitors on the trophozoite food vacuole. Transmission EMs of trophozoite-infected erythrocytes after $12 \mathrm{~h}$ of incubation (1) with no inhibitor $(\times 26,000),(2)$ with 100 $\mu \mathrm{M}$ leupeptin $(\times 34,000)$, or (3) with $140 \mu \mathrm{M} \mathrm{E} 64(\times 22,000)$. In each micrograph the food vacuole $(A)$, parasite cytoplasm $(B)$, and erythrocyte cytoplasm $(C)$ are labeled. 


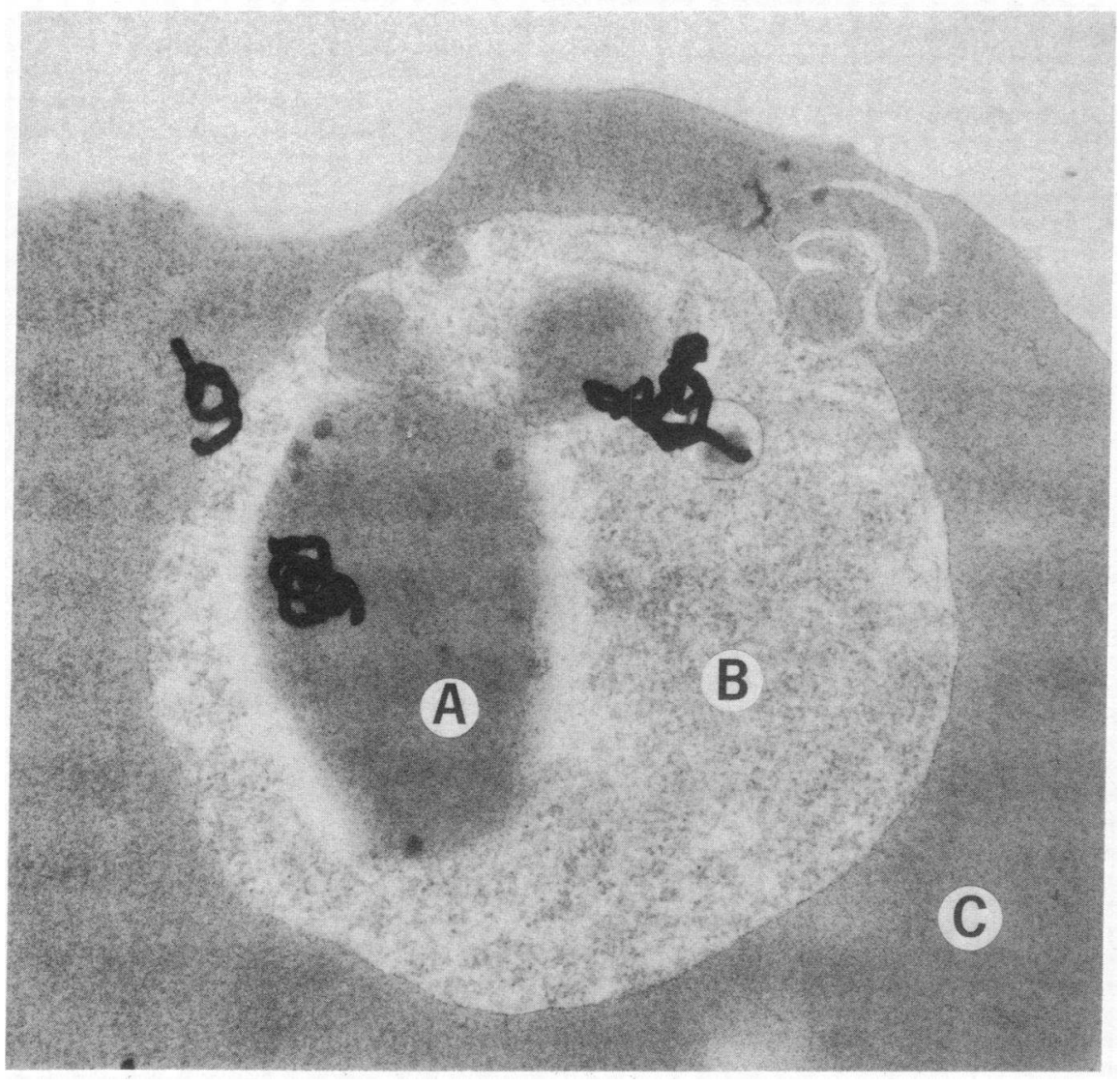

Figure 2. Localization of $\left[{ }^{3} \mathrm{H}\right]$ leupeptin. EM autoradiograph of a trophozoite-infected erythrocyte after a 12-h incubation with $\left[{ }^{3} \mathrm{H}\right]-$ leupeptin $(\times 40,000)$. Electron-dense filaments composed of silver grains indicate the localization of $\left[{ }^{3} \mathrm{H}\right]$ leupeptin to erythrocyte cytoplasm $(C)$ and the trophozoite food vacuole $(A)$. Additional silver grains appear to indicate vacuolar transport of leupeptin (with erythrocyte cytoplasm) through parasite cytoplasm $(B)$ to the food vacuole. inhibition was not as complete as with Azocoll or Z-Val-LeuArg-AMC. Furthermore, the proteolysis of $\left[{ }^{14} \mathrm{C}\right]$ methemoglobin was inhibited in part by pepstatin, indicating that trophozoites also contain aspartic proteinase activity. Leupeptin, E-64, and pepstatin also inhibited the degradation of $\left[{ }^{14} \mathrm{C}\right]$ methemoglobin by the trophozoite extract at $\mathrm{pH} 5.3$ and pH 4.5 (not shown). At each pH studied, the combination of E-64 and pepstatin was more inhibitory than either compound alone (Table I).

Substrate preference of trophozoite proteinase activity Substrate preference was determined by comparing the rates of

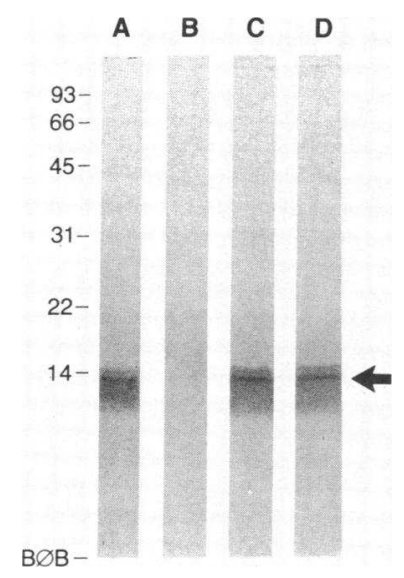

Figure 3. Effect of cysteine proteinase inhibitors on globin degradation by trophozoites. SDSPAGE of proteins solubilized from equal numbers of parasites cultured with and without leupeptin or E-64. Synchronized parasite cultures were incubated with 100 $\mu \mathrm{M}$ leupeptin, $140 \mu \mathrm{M} \mathrm{E}-64$, or no inhibitor for $15 \mathrm{~h}$ before lysis of erythrocyte membranes, multiple washes, and solubilization of trophozoite proteins in SDS sample buffer. The labeled lanes are human hemoglobin (Sigma Chemical Co., $5 \mu \mathrm{g})(A)$, control parasites $(B)$, parasites incubated with leupeptin $(C)$, and parasites incubated with E-64 $(D)$. Arrow shows location of globin chains. hydrolysis of different peptide-AMC substrates at $\mathrm{pH} 6.0$ (Table II). Substrates with arginine at the cleavage site adjacent to a hydrophobic amino acid (Phe or Leu) were preferred over substrates with arginine adjacent to a charged amino acid or substrates lacking arginine.

Identification of an $M_{r}, 28,000$ cysteine proteinase of trophozoites. Proteins of $P$. falciparum trophozoites were extracted with nonreducing electrophoresis sample buffer and

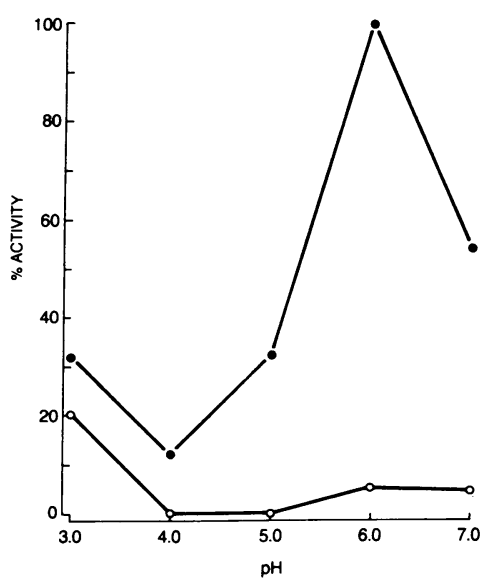

Figure 4. $\mathrm{pH}$ profile of trophozoite proteinase activity. The proteinase activities of a trophozoite extract $(\bullet)$ and an uninfected erythrocyte extract $(0)$ were assayed with Azocoll at different pHs. Results shown are for a single experiment, but multiple assays yielded nearly identical results. Maximum activity $(3.78 \mu \mathrm{g}$ substrate hydrolyzed/ mg trophozoite extract per min) was observed with trophozoite extract at $\mathrm{pH}$ 6.0. Activity of other samples is reported as a percent of the maximum activity. 
Table I. Proteinase Activity of Trophozoite Extract with Different Substrates: Effect of Proteinase Inhibitors and Sulfhydryl Compounds*

\begin{tabular}{lccc}
\hline & \multicolumn{3}{c}{ Substrate } \\
\cline { 2 - 4 } \multicolumn{1}{c}{ Compound added } & Azocoll & Z-V-L-R-AMC ${ }^{\ddagger}$ & {$\left[^{{ }^{14} \mathrm{C}^{\prime} \text { Methemoglobin }}{ }^{\ddagger}\right.$} \\
\hline None (Control) & 100 & 100 & 100 \\
Leupeptin $(10 \mu \mathrm{M})$ & 8.5 & 1.5 & 49.5 \\
E-64 $(10 \mu \mathrm{M})$ & $\mathrm{ND}^{\S}$ & 8.2 & 49.7 \\
NEM $(5 \mathrm{mM})$ & 29.1 & 9.6 & 90.9 \\
Pepstatin $(10 \mu \mathrm{M})$ & 127.7 & 74.3 & 28.6 \\
Pep./E-64" $(10 \mu \mathrm{M})$ & $\mathrm{ND}$ & $\mathrm{ND}$ & 16.9 \\
PMSF $(1 \mathrm{mM})$ & 136.5 & 96.8 & 102.0 \\
1,10-Phen. $(1 \mathrm{mM})$ & 118.8 & 98.4 & 86.9 \\
DTT $(10 \mathrm{mM})$ & 104.2 & 828.0 & 155.2 \\
Cysteine $(10 \mathrm{mM})$ & 367.4 & 864.2 & 200.3 \\
Glutathione $(5 \mathrm{mM})$ & ND & 398.4 & 176.6 \\
& & & \\
\hline
\end{tabular}

* Results (expressed as \% of control activity) of assays of the proteolytic activity of trophozoite extract. The extract was prepared by nitrogen cavitation of trophozoites after the lysis of host erythrocytes. Results shown for each substrate were from a single experiment, but equivalent results were obtained in three or more assays. Control activity for the three substrates was as follows: Azocoll, $2.69 \mu \mathrm{g}$ substrate hydrolyzed/mg trophozoite extract per min; Z-valine-leucinearginine-AMC (Z-V-L-R-AMC), $3.95 \mu \mathrm{mol}$ substrate hydrolyzed $/ \mathrm{mg}$ trophozoite extract per min; $\left[{ }^{14} \mathrm{C}\right]$ methemoglobin, $0.00109 \mu \mathrm{g}$ substrate hydrolyzed/mg trophozoite extract per min. All assays were performed at $\mathrm{pH} 6.0$.

‡ For the Z-V-L-R-AMC assay, trophozoite extract was incubated with $10 \mathrm{mM}$ cysteine for the control and inhibitor (leupeptin, E-64, NEM, pepstatin, PMSF, and 1,10-phenanthroline) assays. For the $\left[{ }^{14} \mathrm{C}\right]$ methemoglobin assay, trophozoite extract was incubated with $10 \mathrm{mM}$ DTT for the control and inhibitor assays. For the sulfhydryl reagent (DTT, cysteine, and glutathione) assays, the controls were incubated with buffer alone.

$\$$ Not done.

"Pepstatin and E-64 (each $10 \mu \mathrm{M}$ ).

electrophoresed in a gelatin substrate polyacrylamide gel. A clear band indicating proteinase activity was detected at $M_{\mathrm{r}}$ 28,000 . This activity was completely inhibited by incubating the gel with $280 \mu \mathrm{M}$ E-64 before staining (Fig. 5). Incubation of the gel with $100 \mu \mathrm{M}$ leupeptin greatly decreased proteinase activity (not shown). Identical results were obtained at $\mathrm{pH} 7.0$ and $\mathrm{pH} 6.0$.

\section{Discussion}

We report evidence that a malarial cysteine proteinase has a critical role in hemoglobin degradation by $P$. falciparum trophozoites. We observed that the incubation of trophozoites with two inhibitors of cysteine proteinases (leupeptin and E-64) caused undigested erythrocyte cytoplasm to accumulate in the parasite food vacuole. We conclude that the effects of leupeptin and E-64 were due to the specific inhibition of a food vacuole cysteine proteinase rather than an unrelated toxicity for the following reasons. (a) Leupeptin at micromolar concentrations inhibits proteinase activity without altering other biochemical processes in mammalian cells (30). (b) The accumulation of erythrocyte cytoplasm in the food vacuole was
Table II. Proteinase Activity of Trophozoite Extract with Different AMC Peptide Substrates*

\begin{tabular}{lc}
\hline \multicolumn{1}{c}{ AMC peptide } & Relative activity \\
\hline Z-Phe-Arg & 100 \\
Z-Val-Leu-Arg & 36.8 \\
Z-Arg-Arg & 19.4 \\
Z-Leu & 7.0 \\
Z-Phe-Pro-Arg & 6.7 \\
Z-Phe & 3.6 \\
Z-Ala-Arg-Arg & 3.1
\end{tabular}

* Results (normalized to 100 for the most effective substrate) of representative assays of the hydrolysis by trophozoite extract of the AMC-peptide fluorogenic substrates listed. Activity of the most effective substrate $=3.86 \mu \mathrm{mol}$ substrate hydrolyzed $/ \mathrm{mg}$ trophozoite extract per min.

caused only by inhibitors of cysteine proteinases. E-64 is a highly specific cysteine proteinase inhibitor (31). (c) $\left[{ }^{3} \mathrm{H}\right]-$ Leupeptin was shown to enter the food vacuole. $(d)$ The effect of leupeptin on the parasites was reversible and the effect of E-64 was not reversible. These observations correlate with the reversible inhibition of mammalian proteinases by leupeptin and the irreversible inhibition of mammalian proteinases by E-64 (30). (e) Intact globin accumulated in parasites incubated with leupeptin and E-64, indicating that the hydrolysis of globin was indeed inhibited.

As predicted by the inhibitor studies, we detected cysteine proteinase activity in trophozoite extracts and identified an $M_{\mathrm{r}}$ 28,000 cysteine proteinase that appeared to account for this activity. We previously showed that the activity of the $M_{\mathrm{r}}$ 28,000 proteinase is expressed only at the trophozoite stage of the life cycle (23) when the food vacuole can be identified morphologically and hemoglobin degradation occurs. The molecular size of the trophozoite proteinase and the acid $\mathrm{pH}$ optimum, inhibitor profile, and substrate preference of the proteinase activity are similar to the biochemical properties of the lysosomal cysteine proteinase cathepsin L (16). The similarities between the malarial enzyme and a lysosomal enzyme further support our hypothesis that the $M_{\mathrm{r}} 28,000$ proteinase is a food vacuole enzyme since the food vacuole appears to be analogous to secondary lysosomes. Although lysosomes con-

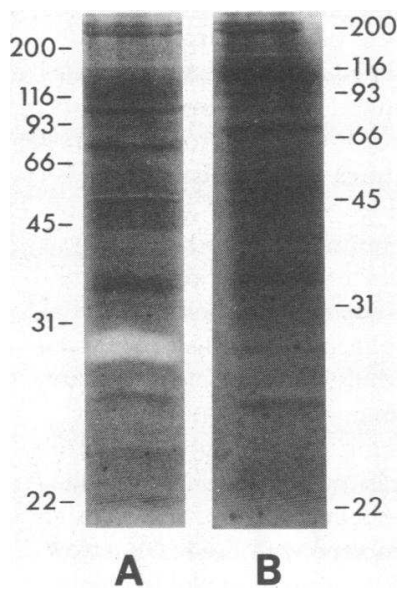

Figure 5. Identification of a trophozoite cysteine proteinase. Gelatin substrate PAGE of trophozoite proteins was performed. In control trophozoites (lane $A$ ) a clear band at $M_{\mathrm{r}} 28,000$ represents proteinase activity. In lane $B$, E-64 was incubated with trophozoites before the addition of sample buffer and was also added to the buffer in which the gel lane incubated after electrophoresis. No evidence of proteinase activity was seen in this lane or with extracts from uninfected erythrocytes (not shown). 
tain multiple acid hydrolases, including cysteine and aspartic proteinases $(16,17)$, lysosomal cysteine proteinases appear to play a key role in the degradation of some proteins (16). For example, the cysteine proteinase inhibitor leupeptin inhibited $70 \%$ of endogenous protein degradation in rat liver cells (30) and caused undegraded protein to accumulate in lysosomes (32-34). Pepstatin, a potent inhibitor of aspartic proteinases, inhibited only $15-20 \%$ of protein degradation (30). The food vacuole of $P$. falciparum may also contain multiple proteinases with different mechanisms of action and different substrate specificities. Indeed, aspartic proteinases have been isolated from several species of Plasmodium (18-20), and we found that pepstatin partially inhibited the proteinase activity of trophozoites when the substrate was $\left[{ }^{14} \mathrm{C}\right]$ methemoglobin. However, pepstatin did not cause the accumulation of erythrocyte cytoplasm in the food vacuole that we observed with leupeptin and E-64. The correlation of the effects of leupeptin and E-64 on the food vacuole of intact parasites with the inhibition of the trophozoite proteinase by the same inhibitors suggests that the $M_{\mathrm{r}} 28,000$ cysteine proteinase has a critical, perhaps rate-limiting, role in hemoglobin degradation by malaria parasites.

We propose the following model for hemoglobin degradation in the food vacuole of $P$. falciparum. After erythrocyte cytoplasm has been ingested and transported to the food vacuole, the proteolysis of globin chains is initiated by a cysteine proteinase that cleaves peptide bonds adjacent to arginine residues on the surface of hemoglobin. We suggest that the $M_{\mathrm{r}}$ 28,000 proteinase has this function. It is intriguing that the sequence leucine-arginine, a preferred substrate of trophozoite proteinase activity, occurs twice in the beta-globin chain at positions that are susceptible to cleavage by the cysteine proteinase clostripain and that have been mapped to exposed sites on intact globin $(35,36)$. The cysteine proteinase that initiates hemoglobin degradation might be stimulated by the sulfhydryl compound glutathione, which is present in high concentrations in erythrocyte cytoplasm (37), and which stimulated trophozoite proteinase activity. The cleavage of exposed peptide bonds and the acid $\mathrm{pH}$ of the food vacuole may denature hemoglobin, making internal hydrophobic residues accessible to cleavage by aspartic proteinases. Cathepsin D, an aspartic proteinase of mammalian lysosomes, has little activity against native proteins, but has considerable activity against denatured proteins, particularly at hydrophobic residues (16). Although the complete proteolytic degradation of hemoglobin is probably a cooperative process requiring multiple proteinases, this model suggests that cleavage by a cysteine proteinase is required to initiate the process. Such a requirement would explain our observation that leupeptin and E-64 caused intact globin to accumulate in the food vacuole. The ensuing inhibition of parasite differentiation and multiplication may have been due to decreased availability of free amino acids for parasite protein synthesis. Specific inhibitors of the $M_{\mathrm{r}} 28,000$ cysteine proteinase may provide new means of antimalarial chemotherapy.

\section{Acknowledgments}

We thank C. T. Peng for supplying $\left[{ }^{3} \mathrm{H}\right]$ leupeptin and C. S. Craik, I. M. Goldstein, R. J. Howard, and R. G. Nelson for their critical reviews of this manuscript.
This work was supported by grants AI-24349 and AI-10645 from the National Institutes of Health and DCB-8603689 from the National Science Foundation, and the UNDP-World Bank-WHO Special Program for Research and Training in Tropical Medicine.

\section{References}

1. Sherman, I. W. 1979. Biochemistry of Plasmodium (malarial parasites). Microbiol. Rev. 43:453-495.

2. Ball, E. G., R. W. McKee, C. B. Anfinsen, W. O. Cruz, and Q. M. Geiman. 1948. Studies on malarial parasites. IX. Chemical and metabolic changes during growth and multiplication in vivo and in vitro. $J$. Biol. Chem. 175:547-571.

3. Groman, N. B. 1951. Dynamic aspects of the nitrogen metabolism of Plasmodium gallinaceum in vivo and in vitro. J. Infect. Dis. 88:126-150.

4. Sherman, I. W., and J. B. Mudd. 1966. Malaria infection (Plasmodium lophurae): changes in free amino acids. Science (Wash. DC). 154:287-289.

5. Cenedella, R. J., H. Rosen, C. R. Angel, and L. H. Saxe. 1968. Free amino-acid production in vitro by Plasmodium berghei. Am J. Trop. Med. Hyg. 17:800-803.

6. Barry, D. N. 1982. Metabolism of Babesia parasites in vitro: amino acid production by Babesia rodhaini compared to Plasmodium berghei. Aust. J. Exp. Biol. Med. Sci. 60:175-180.

7. Zarchin, S., M. Krugliak, and H. Ginsburg. 1986. Digestion of the host erythrocyte by malaria parasites is the primary target for quinoline-containing antimalarials. Biochem. Pharmacol. 35:24352442.

8. Fulton, J. D., and P. T. Grant. 1956. The sulphur requirements of the erythrocytic form of Plasmodium knowlesi. Biochem. J. 63:274-282.

9. Sherman, I. W., and L. Tanigoshi. 1970. Incorporation of ${ }^{14} \mathrm{C}$ amino-acids by malaria (Plasmodium lophurae). IV. In vivo utilization of host cell hemoglobin. Int. J. Biochem. 1:635-637.

10. Theakston, R. D. G., S. A. Fletcher, and B. G. Maegraith. 1970. The use of electron microscope autoradiography for examining the uptake and degradation of haemoglobin by Plasmodium berghei. Ann. Trop. Med. Parasitol. 64:63-71.

11. Aikawa, M. 1971. Plasmodium: the fine structure of malarial parasites. Exp. Parasitol. 30:284-320.

12. Yayon, A., R. Timberg, S. Friedman, and H. Ginsburg. 1984. Effects of chloroquine on the feeding mechanism of the intraerythrocytic human malarial parasite Plasmodium falciparum. J. Protozool. 31:367-372.

13. Yamada, K. A., and I. W. Sherman. 1979. Plasmodium lophurae: composition and properties of hemozoin, the malarial pigment. Exp. Parasitol. 48:61-74.

14. Yayon, A., Z. I. Cabantchik, and H. Ginsburg. 1984. Identification of the acidic compartment of Plasmodium falciparum-infected human erythrocytes as the target of the antimalarial drug chloroquine. EMBO (Eur. Mol. Biol. Organ.) J. 3:2695-2700.

15. Krogstad, D. J., P. H. Schlesinger, and I. Y. Gluzman. 1985. Antimalarials increase vesicle $\mathrm{pH}$ in Plasmodium falciparum. J. Cell Biol. 101:2302-2309.

16. Bond, J. S., and P. E. Butler. 1987. Intracellular proteases. Annu. Rev. Biochem. 56:333-364.

17. Krogstad, D. J., and P. H. Schlesinger. 1987. Acid-vesicle function, intracellular pathogens, and the action of chloroquine against Plasmodium falciparum. N. Engl. J. Med. 317:542-549.

18. Gyang, F. N., B. Poole, and W. Trager. 1982. Peptidases from Plasmodium falciparum cultured in vitro. Mol. Biochem. Parasitol. 5:263-273.

19. Sherman, I. W., and L. Tanigoshi. 1983. Purification of Plasmodium lophurae cathepsin D and its effects on erythrocyte membrane proteins. Mol. Biochem. Parasitol. 8:207-226. 
20. Vander Jagt, D. L., L. A. Hunsaker, and N. M. Campos. 1986. Characterization of a hemoglobin-degrading, low molecular weight protease from Plasmodium falciparum. Mol. Biochem. Parasitol. 18:389-400.

21. Trager, W., and J. B. Jensen. 1976. Human malaria parasites in continuous culture. Science (Wash. DC). 193:673-675.

22. Lambros, C., and J. P. Vanderberg. 1979. Synchronization of Plasmodium falciparum erythrocytic stages in culture. J. Parasitol. 65:418-420.

23. Rosenthal, P. J., K. Kim, J. H. McKerrow, and J. H. Leech. 1987. Identification of three stage-specific proteinases of Plasmodium falciparum. J. Exp. Med. 166:816-821.

24. Jensen, J. B. 1978. Concentration from continuous culture of erythrocytes infected with trophozoites and schizonts of Plasmodium falciparum. Am. J. Trop. Med. Hyg. 27:1274-1276.

25. Peng, C. T., and O. Buchman. 1985. Tritium exchange labelling of compounds containing $-\mathrm{NO}_{2},-\mathrm{I},-\mathrm{C}=\mathrm{C}-$, and $-\mathrm{C}=\mathrm{O}$ groups. Tetrahedron Lett. 26:1375-1378.

26. Aikawa, M. 1972. High-resolution autoradiography of malarial parasites treated with ${ }^{3} \mathrm{H}$-chloroquine. Am. J. Pathol. 67:277-280.

27. Laemmli, U. K. 1970. Cleavage of structural proteins during the assembly of the head of bacteriophage T4. Nature (Lond.). 227:680-685.

28. Heussen, C., and E. B. Dowdle. 1980. Electrophoretic analysis of plasminogen activators in polyacrylamide gels containing sodium dodecyl sulfate and copolymerized substrates. Anal. Biochem. 102:196-202.
29. Dluzewski, A. R., K. Rangachari, R. J. M. Wilson, and W. B. Gratzer. 1986. Plasmodium falciparum: protease inhibitors and inhibition of erythrocyte invasion. Exp. Parasitol. 62:416-422.

30. Seglen, P. O. 1983. Inhibitors of lysosomal function. Methods Enzymol. 96:737-764.

31. Barrett, A. J., A. A. Kembhavi, and K. Hanada. 1981. E-64 [L-trans-epoxysuccinyl-leucyl-amido(4-guanidino)butane] and related epoxides as inhibitors of cysteine proteinases. Acta Biol. Med. Germ. 40:1513-1517.

32. Aronson, N. N., P. A. Dennis, and W. A. Dunn. 1981. Metabolism of leupeptin and its effect on autophagy in the perfused rat liver. Acta Biol. Med. Germ. 40:1531-1538.

33. Tolleshaug, H., and T. Berg. 1981. The effect of leupeptin on intracellular digestion of asialofetuin in rat hepatocytes. Exp. Cell Res. 134:207-217.

34. Kovacs, A. L., A. Reith, and P. O. Seglen. 1982. Accumulation of autophagosomes after inhibition of hepatocytic protein degradation by vinblastine, leupeptin or a lysosomotropic amine. Exp. Cell Res. 137:191-201.

35. Craik, C. S., S. R. Buchman, and S. Beychok. 1980. Characterization of globin domains: heme binding to the central exon product. Proc. Natl. Acad. Sci. USA. 77:1384-1388.

36. Craik, C. S., S. Sprang, R. Fletterick, and W. J. Rutter. 1982. Intron-exon splice junctions map at protein surfaces. Nature (Lond.). 299:180-182.

37. Meister, A., and M. E. Anderson. 1983. Glutathione. Annu. Rev. Biochem. 52:711-760. 